\title{
Production planning problem with market impact under demand uncertainty
}

\author{
Takuya AOYAMA*, Tatsushi NISHI ${ }^{*}$ and Guoqing ZHANG ${ }^{* *}$ \\ ${ }^{*}$ Graduate School of Engineering Science, Osaka University \\ 1-3 Machikaneyama-cho, Toyonaka 560-8531, Japan \\ E-mail: nishi@sys.es.osaka-u.ac.jp \\ ** Department of Mechanical, Automotive \& Material Engineering, University of Windsor \\ 401 Sunset Avenue Windsor, Ontario, Canada
}

Received: 28 September 2016; Revised: 7 February 2017; Accepted: 20 March 2017

\begin{abstract}
In this paper, we consider the production planning problem for a single manufacturer with the investment to improve the market impact under demand uncertainty. In the mathematical model, the average demand increases if the investment of market impact is increased for each product. The objective is to maximize the total profit with a piecewise linear investment cost and a budget constraint. The problem is formulated as a mixed integer nonlinear programming problem. A solution procedure based on Lagrangian relaxation is developed to solve the problem efficiently. In the proposed method, an analytical solution of the newsboy problem is effectively used to derive the lower and upper bounds. The condition of the concavity of the profit function is derived. The effectiveness of the proposed method is confirmed through computational experiments.
\end{abstract}

Key words : Lagrangian relaxation, Advertising, CSR, Investment, Supply chain, Uncertain demand, Market impact

\section{Introduction}

In supply chains, manufacturing companies have recognized the importance of market impact. The market impact is the effect of the product demands of various marketing activities such as corporate social responsibility (CSR) or investment for advertising. The advertising is one way of promotional campaign which is used in various companies in order to improve the brand image of their products to customers. The advertising has a positive effect on the consumer's buying behavior. SeyedEsfahani et al. (2011) studied a vertical cooperative advertising along with pricing decisions in a supply chain. In this model, the demand is influenced by both price and advertisement. Zhang et al. (2013) proposed a dynamic cooperative advertising model for a manufacturer-retailer supply chain taking into account the impact of advertising on the reference price. Yue et al. (2006) studied the coordination of cooperative advertisement in a manufacturer-retailer supply chain when the manufacturer offers price deductions to customers. Li et al. (2002) proposed three strategic models for determining equilibrium marketing and investment effort levels for a manufacturer and a retailer in two-members supply chain. In those models, they addressed the impact of brand name investments, local advertising, and sharing policy on cooperative advertising programs. Giri and Sharma (2014) studied a two-echelon supply chain comprising one manufacturer and two competing retailers with advertising cost dependent demand. In their model, two retailers compete with each other in advertising with different sales costs.

CSR is related to human rights and environmental issues to influence product demands by investing in those activities. The CSR activity encourages manufacturing companies to take responsibility for social cooperative actions to enhance a positive impact on environments, stakeholders, consumers, employees, investors, communities, and others. For instance, green procurement is to achieve sustainable supply chains reducing environmental load by trading with less CO2 emissions for suppliers. Fair trade is introduced to preserve the prohibition of child labor, human rights violations and environmental 
destruction taking responsibilities of social corporations and consumers. These efforts may include investment from manufacturing companies to improve the CSR performance level. If the investment is higher, the higher CSR performance level is achieved and then results in larger market demands. Hsueh (2014) proposed a supply chain planning model that was integrated with the decisions of manufacturers' investments to take CSR activities. They proposed a new revenue sharing contract on supply chain coordination with investment in CSR. Ni and Li (2012) addressed a game-theoretic analysis of CSR decisions in SCM. Ni et al. (2010) also studied the model where suppliers take a quadratic cost function in order to achieve CSR performance level. Franz et al. (2013) studied the model to determine whether the firm's CSR activities are expanded or reduced to maximize its value of profit. Cruz (2008), (2009), (2013) explored the dynamic evolution of the product flows associated with product prices as well as the levels of CSR activities on the network until an equilibrium is achieved.

Advertising and CSR activity are common in relation to depending on the demand of products. In this paper, we consider the activities such as advertising and CSR to enhance the market impact. The brand image of a manufacturer's product is improved by increasing investment. In conventional planning models with CSR investment decisions, investment cost for risk aversion has not been considered. The variance of profit with respect to investment is often incurred as a risk measure. However, the model becomes too complicated when these risk measures are directly introduced because these costs are usually represented as a quadratic term in the objective function.

In this paper, we consider the production planning problem for a single manufacturer with investment under demand uncertainty. The investment cost is incurred by the piecewise linear function with respect to the amount of investment. We develop a single period production planning model with investment taking account of sales profit, inventory cost, opportunity cost, and production cost with a budget constraint under demand uncertainty. The problem can be reformulated as a mixed integer nonlinear programming problem. To the best of our knowledge, the strategic planning problem with investment decisions with the piecewise liner costs under demand uncertainty has not been studied yet.

The production planning models under demand uncertainty have been studied over many years. Shi et al. (2011) proposed the extension of the newsboy problem to maximize the manufacturer's expected profit under uncertain demand. They solved the problem by using the Lagrangian relaxation method. Petkov and Maranas (1997) proposed the multi-period production planning problem under uncertain demand. The stochastic problem was reformulated into a deterministic equivalent form in order to maximize the expected profit. Zhang and Ma (2009) proposed the production planning problem with quantity discounts for the procurement from suppliers with the piecewise linear purchase cost. Zhang (2010) introduced an analytical model with piecewise linear production costs. An extension of the problem is to consider a price discount in newsboy models, which is a popular policy used by suppliers to promote their products.

Aoyama and Nishi (2015) proposed a supply chain planning with CSR investment under uncertain demand. However, there was no proof of the concavity of the profit function and the solution strategies had not been established yet. In this paper, we adopt the model that the average value of the demand is increased in accordance with the amount of investments. Furthermore, a solution procedure based on Lagrangian relaxation is proposed to solve the problem efficiently. The Lagrangian relaxation method is used to obtain a tight lower and upper bound to ensure the optimality of the solution for production planning problems (Nishi et al., 2008). The analytical solutions derived from the unconstrained newsboy problem are used to generate a feasible solution using heuristics. The computational experiments are conducted for large scale cases with 2-100 products, 2-10 segments of the piecewise linear function. The sensibility analysis is conducted to investigate the impact of the cost parameters on the total profit under demand uncertainty. The main contributions of the paper are summarized as follows.

- A production planning model with the piecewise linear investment costs for multi-products is developed.

- A solution procedure based on Lagrangian relaxation is developed.

- A small duality gap can be obtained for 2-100 products, 2-10 segments by the proposed method even though a general-purpose mixed integer nonlinear programming problem solver requires more than 3600 seconds.

- The condition of the concavity of the profit function is derived.

The rest of the paper is organized as follows. Section 2 introduces literature review. Section 3 provides the modeling of production planning with investment under demand uncertainty. Section 4 develops a solution procedure based on Lagrangian relaxation. Section 5 presents computational experiments. Section 6 concludes the paper and states future works. 


\section{Literature review}

The production planning problem with market impact has been reported recently. Many companies have recognized the significance of marketing activities such as the investment for advertising or CSR activities. There are various production planning with advertisement decisions recently. The advertising is used to provide the brand knowledge of their products to the customers. SeyedEsfahani et al. (2011) studied a vertical cooperative advertising along with pricing decisions in a manufacturer-retailer supply chain. Vertical cooperative advertising is a marketing strategy in which the retailer invests in local advertising and the manufacturer usually shares a part of the retailer's local advertising costs. In their study, demand is influenced by both price and advertisement. They compared four game-theoretic models including Nash, Stackelberg-manufacturer, Stackelberg-retailer and cooperative game. In the latter case, both of the manufacturer and the retailer obtained the highest profit level. Zhang et al. (2013) proposed a dynamic cooperative advertising model for a manufacturer-retailer supply chain taking into account the impact of advertising on the reference price. They analyzed how the reference price effect would influence the decisions of all channel members. It was assumed that both consumer's goodwill and reference price for the product were influenced by the advertising. Furthermore, the advertising level, the consumer's goodwill and the reference price had a positive effect on sales. By introducing game theory, they formulated the optimal decisions of the manufacturer and the retailer in the Stackelberg game and cooperative game. Yue et al. (2006) studied the coordination of cooperative advertisement in a manufacturer-retailer supply chain when the manufacturer offers price deductions to customers. They examined two cases. The one is the case where the manufacturer is a leader. The other is one where the manufacturer and retailer are partners. In addition, they proposed a two-step bargaining model that described how to share the profit based on bargaining powers. Furthermore, it determines the manufacturer's share of local advertisement and the associated price level. Li et al. (2002) developed three strategic models for determining the equilibrium marketing and investment effort levels for a manufacturer-retailer supply chain. They addressed the impact of brand name investments, local advertising, and sharing policy on co-op advertising programs. The first model provided a formal normative approach for analyzing the traditional cooperative advertising program where the manufacturer is a leader. By the second model, a further analysis on the manufacturer-dominated relationship was obtained. The third model introduced the recent market trend of retailing power shifts from manufacturers to retailers. Giri and Sharma (2014) studied a two-echelon supply chain comprising one manufacturer and two competing retailers with advertising cost dependent demand. The two retailers compete with each other in advertising and they have different sales costs. The manufacturer uses one of the two pricing models. One is the model where the manufacturer sets the same wholesale price for both of the retailers irrespective of the difference in their sales costs. The other is the model where the manufacturer sets different wholesale prices to the retailers depending on their costs. In both of the models, they derived the retailers' and manufacturer's optimal strategies. In order to examine the theoretical results developed in each model, a numerical experiment was conducted. From the above literature, various pricing models with the advertising were studied. However, the production planning problem with investment for advertising has not been studied.

Planning with CSR is also becoming increasingly popular. Many companies choose to have more responsibilities to increase the brand image of the company. Recent studies focus on contracts of supply chain coordination with CSR. Hsueh (2014) has addressed that the CSR cost is only incurred to the manufacturer, and the CSR performance level is characterized by a performance function $g(x)(0 \leq g(x) \leq 1)$ where $x$ is the amount of investment. In general, higher CSR performance function level requires higher CSR cost, but it can cause a greater market demand. Therefore, the market demand is assumed to follow a normal distribution $\left(\mu_{0}+a g(x), \sigma^{2}\right)$ where $\mu_{0}$ is the mean of the distribution when no CSR activities are adopted. The parameter $a$ is a positive constant indicating the maximum increase of the mean due to CSR performance. Hsueh and Chang (2008) have also explored the equilibrium results of a decentralized supply chain network. The benefits of CSR can be obtained in the decentralized supply chain as well as centralized one. In other words, applying CSR to a decentralized supply chain network can increase the profits of the entire supply chain in an equilibrium. Franz et al. (2013) has investigated how companies should create plan corporate social responsibility. The dynamic analysis started with a company's intertemporal optimization problem is conducted, and then proceeded to analyze interactions with other companies. The aim was to develop a framework that can explain the variance of CSR activities, where at the same time the question of whether these activities are sustainable, was addressed. As an example, they stated that the CSR projects are: environmental reports, philanthropically supports and sponsoring, energy and environmental management, mentoring and educational programs for workers, family friendly workplaces and alike. Further examples are higher wages, improvements of working conditions and a switch to local sourcing. Ni et al. (2010) indicated that the key issues were to determine who should be allocated as the responsibility holders with the right of offering the contract and how this 
right should be appropriately restricted. Game-theoretical analyses are conducted on six games resulting from different interaction schemes between the supplier and the company to derive their corresponding equilibriums. Comparative institutional analyses are then examined to determine the optimal social responsibility allocation based on both economic and CSR performance criteria. The main results were provided in a series of propositions and their implications to the real-world business practice. Furthermore, Cruz (2008), (2009), (2010) has developed a dynamic framework for the modeling and analysis of supply chain networks with corporate social responsibility through an integrated environmental decision-making. Through a multilevel supply chain network, they represent the multi-criteria decision-making behavior of the various decision-makers (manufacturers, retailers, and consumers) which includes the maximization of profit, the minimization of emission (waste), and the minimization of risk. They explored the dynamic evolution of the product flows, the associated product prices, as well as the levels of social responsibility activities on the network until an equilibrium is achieved.

In the conventional studies, CSR activities are performed to improve for the environment, employee welfare, stakeholder and voluntariness. It has been made an assumption that CSR activities influence to manufacturers' production cost, wholesale price and social benefit. However, in these studies, the risk aversion for investment has not been addressed. In this paper, we consider the production planning with the investment in advertising and CSR activities under uncertain demand in order to highlight corporate brand. We assume that demand for each product becomes larger when investment level is higher. Also, we consider the piecewise linear investment cost with a budget constraint to represent a wide range of risk aversion for investment in the production planning models.

\section{Modeling production planning with market impact \\ 3.1. Problem Definition}

The outline of the production planning with market impact is shown in Fig. 1. In this model, a single manufacturer who produces multiple products makes a decision of annual strategic production planning. A single manufacturer creates the production planning with investment to improve the market impact such as advertising, environmental preservation, training employees and compliance. As a result, the manufacturer can improve the brand power by these activities. For example, if the investment of the manufacturer in its advertising campaign is large, customers make better impression for the manufacturer and products. Then, the demand of each product becomes larger. However, the advertising is different from the CSR activities in that the manufacturer improves its publicity for each product in the advertising activity. On the other hand, the CSR activities influence its brand power. Hsueh (2014) regarded CSR activities as investment to customers. He modeled the planning problem for a single product. However, the investment for the advertising is often considered for multiple products. In the proposed model, let $\mu_{i}$ represent the average of the demand for product $i$, and let $\sigma_{i}^{2}$ represent the variance of demands for product $i$. The manufacturer invests to the market impact for each product. Then, customers get a better impression of the manufacturer and the average of demand for a product increases as the investment amount increases. The average of the uncertain demand $\mu_{i}^{\prime}$ on the amount of investment $\mu_{i}^{\prime}=\mu_{i}+g\left(x_{i}\right)$ where $g\left(x_{i}\right)$ is a non-decreasing function with respect to $x_{i}$. Generally, effects of market impact gradually decrease when the investment amount is higher. We set a general equation $g\left(x_{i}\right)=a x_{i}^{m}(0 \leq m \leq 1)$ in order to represent the function where the increasing rate of average demand is decreased when investment $x_{i}$ is increased. Based on the demand, the investment amount $x_{i}$ and the production quantity $y_{i}$ are determined to maximize the total profit.

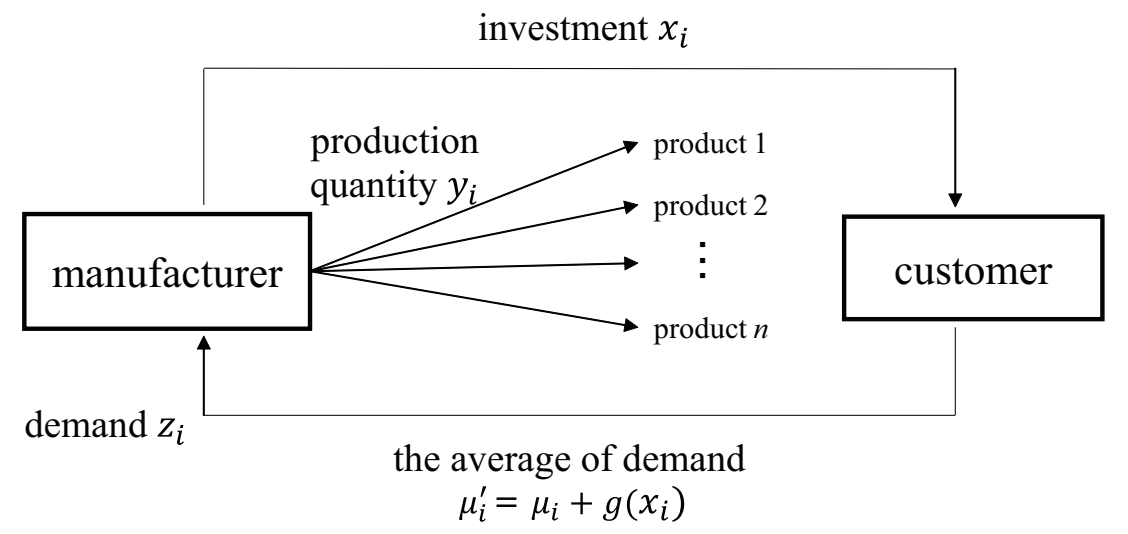

Fig. 1 Production planning model with market impact 
- Annual production planning problem is considered. Therefore, the planning horizon is one.

- The probability distribution of uncertain demand follows the normal distribution.

- The demand of each item is uncertain, but the average and the probability density function are known.

- Each investment is independent of each other.

- The manufacturer invests for the market impact of each product.

- The manufacturer has enough raw materials to produce a product.

- Products are transported to customers directly.

Advertising and CSR activity are different in investment timing. Advertising is considered in the short term, whereas CSR activity is considered for the long term. Conventional works on advertising are classified into single period models (SeyedEsfahani et al., 2011; Zhang et al., 2014) and multi-period models (Zhang et al. 2013). Although advertising is considered in the short term, static models with single period models have been studied in many studies (SeyedEsfahani et al., 2011; Zhang et al. 2014). Therefore, we only focus on a single period production planning model with market impact of advertising or CSR activities. Also, we consider the planning under uncertain demand. The originality is to not only introduce the piecewise linear investment costs but also to consider investment for the multi-products. The investment for a single product is conducted in conventional studies. In the advertising, the investment for the each product is often conducted. In this model, for simplification, there are enough raw materials and products are transported to customers directly. The objective function is the total profit including sales revenue, shortage penalties, overstocking costs, production costs, and the risk of investment. The following notations are used in the formulation. We consider the budget constraint which limits the total amount of investment for each product. In the model, the manufacturer wants to invest to increase its profit. However, in practice, there is the risk of investment. The variance of profitability of investment $x_{i}$ is often used as a risk measure which is expressed by $x^{T} S x$, where $x=\left[x_{1}, \ldots, x_{n}\right]^{T}$ is the portfolio and $S$ is the variancecovariance matrix. $x_{i}$ is the investment ratio of product $i$. The problem becomes more complicated if the quadratic term is included. We introduce the piecewise linear investment cost and the investment segment for each product. We assume that there is the investment cost in each segment.

Hsueh (2014) addressed the production planning problem with CSR investment for a single product. However, in general, the manufacturer produces multiple products. The investment for multiple products is important in the production planning problem. Also, in general, the risk of investment always occurs if the investment is conducted. Therefore, it is important to consider the production planning with the risk of investment when the investment to market is considered.

\subsection{Problem Formulation}

\section{Indices}

$i=1, \ldots, n:$ index of products, where $n$ is the total number of products

$j=1, \ldots, k_{i}$ : index of investment segment $j$ for product $i$

$k_{i}$ : the number of investment segments for product $i$

\section{Decision variables}

$x_{i}$ : amount of investment for product $i$

$x_{i j}$ : amount of investment for product $i$ at segment $j$

$y_{i}$ : production quantity of product $i$

$w_{i j}$ : binary variable that takes 1 if product $i$ is invested at segment $j$, and 0 otherwise.

\section{Parameters}

$\alpha_{i}$ : unit shortage penalty of product $i$

$\beta_{i}$ : unit overstocking cost of product $i$

$c_{i j}$ : unit investment cost of product $i$ on segment $j$

$e_{i}$ : unit production cost of product $i$

$r_{i}$ : unit sales revenue of product $i$

$H$ : upper limit of the total amount of investment

$h_{i j}^{U}$ : upper bound of the investment quantity of product $i$ on segment $j$

$h_{i j}^{L}$ : lower bound of the investment quantity of product $i$ on segment $j$

$z_{i}$ : random variable of demand of product $i$

$f\left(z_{i}\right)$ : probability density function followed by the demand of product $i$ 
$F\left(z_{i}\right)$ : cumulative distribution followed by the demand of product $i$

$\mu_{i}$ : average of the demand of product $i$

$\sigma_{i}$ : variance of the demand of product $i$

We have the following investment relationships $h_{i, j-1}^{L}<h_{i, j-1}^{U}<h_{i, j}^{L}<h_{i, j}^{U}$, for all $i$, and $c_{i, j-1}<c_{i, j}$, for all $i$, and $j=2, \ldots, k_{i}$. Fig. 2 shows an example of the piecewise linear investment cost corresponding the investment amount.

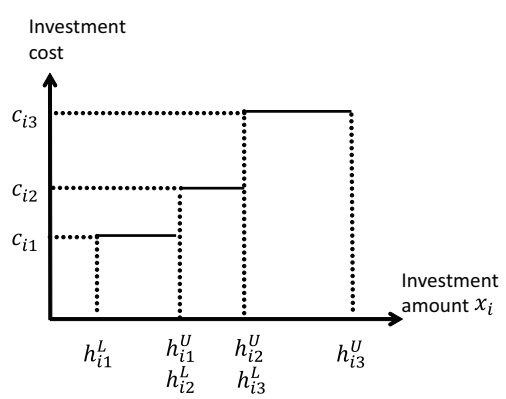

Fig. 2 Example of the piecewise linear investment cost

We assume that the average of the uncertain demand $\mu_{i}^{\prime}=\mu_{i}+g\left(x_{i}\right)$ depending on the investment amount. The original problem $(P)$ can be formulated as follows.

$$
\begin{aligned}
(P) \max J= & \sum_{i=1}^{n}\left\{\int_{0}^{y_{i}} r_{i} z_{i} f\left(z_{i}\right) d z_{i}+\int_{y_{i}}^{\infty} r_{i} y_{i} f\left(z_{i}\right) d z_{i}-\int_{0}^{y_{i}} \beta_{i}\left(y_{i}-z_{i}\right) f\left(z_{i}\right) d z_{i}\right. \\
& \left.-\int_{y_{i}}^{\infty} \alpha_{i}\left(z_{i}-y_{i}\right) f\left(z_{i}\right) d z_{i}-e_{i} y_{i}-\sum_{j=1}^{k_{i}} c_{i j} x_{i j}\right\}
\end{aligned}
$$

The first term represents the expected revenue when the production quantity of product $i$ is greater than the actual market demand. The second term is the expected revenue when the actual demand is larger than the production quantity. The third term is the overstocking cost. The fourth term is the shortage penalty. The fifth term is the production cost. The last term is the piecewise linear investment cost. $\alpha_{i}$ is the unit shortage penalty of product $i, \beta_{i}$ is the unit overstocking cost of product $i, e_{i}$ is the unit production cost of product $i$, and $c_{i j}$ is the unit investment cost of product $i$ on investment segment $j$.

$$
\begin{array}{ll}
\text { s.t. } & \sum_{i=1}^{n} x_{i} \leq H \\
& x_{i j} \leq h_{i j}^{U} w_{i j} \quad(\forall i, \forall j) \\
& x_{i j} \geq h_{i j}^{L} w_{i j} \quad(\forall i, \forall j) \\
& \sum_{j=1}^{k_{i}} w_{i j}=1 \quad(\forall i) \\
& x_{i}=\sum_{j=1}^{k_{i}} x_{i j} \quad(\forall i) \\
& x_{i} \geq 0, x_{i j} \geq 0, y_{i} \geq 0, z_{i} \geq 0 \quad(\forall i, \forall j) \\
& w_{i j} \in\{0,1\} \quad(\forall i, \forall j) \quad(\forall i) \\
& z_{i} \sim N\left(\mu_{i}+g\left(x_{i}\right), \sigma_{i}^{2}\right) \quad(\quad
\end{array}
$$

Constraint (2) is the upper limit of the total amount of investment. Constraints (3) and (4) ensure that the amount of investment is placed at each interval of the segment. Constraints (5) and (6) ensure that only one investment segment is eventually selected to the investment amount. Constraints (7) imply the non-negativity of each decision variable. Constraints (8) ensure that each variable is a binary variable. Constraints (9) represent that the demand of product $i$ follows the normal distribution $N\left(\mu_{i}+g\left(x_{i}\right), \sigma_{i}^{2}\right) . \mu_{i}+g\left(x_{i}\right)$ represents the average of the uncertain demand of product $i$. The problem is formulated as a mixed integer nonlinear programming problem which is difficult to be solved by commercial-solvers. 


\subsection{Stochastic formulation}

The objective function is the expected value due to the demand uncertainty. However, it is difficult to solve the problem by general-purpose solvers if the demand follows the normal distribution. Therefore, the total revenue of (1), the total overstocking cost of the third term of (1) and the total shortage penalty of the fourth term of (1) are required to be reformulated. Petkov and Maranas (1997) addressed the normalization technique of the expectation of the costs under demand uncertainty. In their model, the objective function of the production planning problem under demand uncertainty is reformulated by the normalization of the probability distribution. By applying the normalization technique to our formulation, the expected values of the sales profits, the overstocking costs and the total shortage penalties are reformulated as the following equations. These reformulations are shown in Appendix A. The reformulation can also found in Yin et al. (2014), Yin and Nishi (2014).

$$
\begin{aligned}
& \sum_{i=1}^{n}\left\{\int_{0}^{y_{i}} r_{i} z_{i} f\left(z_{i}\right) d z_{i}+\int_{y_{i}}^{\infty} r_{i} y_{i} f\left(z_{i}\right) d z_{i}\right\}=\sum_{i=1}^{n} r_{i}\left[\left(\mu_{i}-y_{i}\right) F\left(\frac{y_{i}-\mu_{i}}{\sigma_{i}}\right)-\sigma_{i} f\left(\frac{y_{i}-\mu_{i}}{\sigma_{i}}\right)+y_{i}\right] \\
& \sum_{i=1}^{n} \int_{y_{i}}^{\infty} \alpha_{i}\left(z_{i}-y_{i}\right) f\left(z_{i}\right) d z_{i}=\sum_{i=1}^{n}-\alpha_{i}\left[\left(1-F\left(\frac{y_{i}-\mu_{i}}{\sigma_{i}}\right)\right)\left(y_{i}-\mu_{i}\right)-\sigma_{i} f\left(\frac{y_{i}-\mu_{i}}{\sigma_{i}}\right)\right] \\
& \sum_{i=1}^{n} \int_{0}^{y_{i}} \beta_{i}\left(y_{i}-z_{i}\right) f\left(z_{i}\right) d z_{i}=\sum_{i=1}^{n} \beta_{i}\left[\left(y_{i}-\mu_{i}\right) F\left(\frac{y_{i}-\mu_{i}}{\sigma_{i}}\right)+\sigma_{i} f\left(\frac{y_{i}-\mu_{i}}{\sigma_{i}}\right)\right]
\end{aligned}
$$

In these equations, $f\left(z_{i}\right)$ is the probability density function and $F\left(z_{i}\right)$ is the cumulative distribution. The objective function is reformulated as follows:

$$
\begin{aligned}
J= & \sum_{i=1}^{n}\left\{r_{i}\left[\left(\mu_{i}-y_{i}\right) F\left(\frac{y_{i}-\mu_{i}}{\sigma_{i}}\right)-\sigma_{i} f\left(\frac{y_{i}-\mu_{i}}{\sigma_{i}}\right)+y_{i}\right]-\beta_{i}\left[\left(y_{i}-\mu_{i}\right) F\left(\frac{y_{i}-\mu_{i}}{\sigma_{i}}\right)+\sigma_{i} f\left(\frac{y_{i}-\mu_{i}}{\sigma_{i}}\right)\right]\right. \\
& \left.+\alpha_{i}\left[\left(1-F\left(\frac{y_{i}-\mu_{i}}{\sigma_{i}}\right)\right)\left(y_{i}-\mu_{i}\right)-\sigma_{i} f\left(\frac{y_{i}-\mu_{i}}{\sigma_{i}}\right)\right]-e_{i} y_{i}-\sum_{j=1}^{k_{i}} c_{i j} x_{i j}\right\}
\end{aligned}
$$

The average of the uncertain demand $\mu_{i}^{\prime}$ depends on the amount of investment $\mu_{i}^{\prime}=\mu_{i}+g\left(x_{i}\right)$ where $g\left(x_{i}\right)$ is a nondecreasing function with respect to $x_{i}$.

$$
\mu_{i}^{\prime}=\mu_{i}+g\left(x_{i}\right)
$$

Then, we can reformulate (13).

$$
\begin{aligned}
J= & \sum_{i=1}^{n}\left\{r_{i}\left[\left(\mu_{i}+g\left(x_{i}\right)-y_{i}\right) F\left(\frac{y_{i}-\mu_{i}-g\left(x_{i}\right)}{\sigma_{i}}\right)-\sigma_{i} f\left(\frac{y_{i}-\mu_{i}-g\left(x_{i}\right)}{\sigma_{i}}\right)+y_{i}\right]\right. \\
& +\alpha_{i}\left[\left(1-F\left(\frac{y_{i}-\mu_{i}-g\left(x_{i}\right)}{\sigma_{i}}\right)\right)\left(y_{i}-\mu_{i}-g\left(x_{i}\right)\right)-\sigma_{i} f\left(\frac{y_{i}-\mu_{i}-g\left(x_{i}\right)}{\sigma_{i}}\right)\right] \\
& -\beta_{i}\left[\left(y_{i}-\mu_{i}-g\left(x_{i}\right)\right) F\left(\frac{y_{i}-\mu_{i}-g\left(x_{i}\right)}{\sigma_{i}}\right)+\sigma_{i} f\left(\frac{y_{i}-\mu_{i}-g\left(x_{i}\right)}{\sigma_{i}}\right)\right] \\
& \left.-e_{i} y_{i}-\sum_{j=1}^{k_{i}} c_{i j} x_{i j}\right\}=\sum_{i=1}^{n} J_{i}
\end{aligned}
$$

Equation (15) shows that the objective function can be represented as an additive expression for each product.

\section{Lagrangian relaxation approach}

It is difficult to find an optimal solution by commercial solvers if the scale of the original problem is large. The Lagrangian relaxation is applied to obtain a better upper and lower bound effectively.

\subsection{Lagrangian relaxation}

The investment constraint (2) is relaxed by introducing Lagrange multiplier $\lambda$ to construct the following Lagrangian relaxation problem $(L R)$.

$$
\begin{aligned}
& (L R) \quad \max L \\
& L=\sum_{i=1}^{n} J_{i}+\lambda\left(H-\sum_{i=1}^{n} x_{i}\right)=\sum_{i=1}^{n}\left(J_{i}-\lambda x_{i}\right)+\lambda H
\end{aligned}
$$




$$
\begin{aligned}
& =\sum_{i=1}^{n} L_{i}+\lambda H \\
& \text { s.t. } \quad(2)-(9)
\end{aligned}
$$

The Lagrangian relaxation problem $(L R)$ is decomposed into $n$ sub-problems of maximizing the function $L_{i}$ for each product $i$.

\subsection{Solution of sub-problems}

The sub-problem to maximize $L_{i}$ is formulated as $\left(L P_{i}\right)$ as follows.

$$
\begin{aligned}
\left(L P_{i}\right) \quad \max \quad L_{i}= & r_{i}\left[\left(\mu_{i}+g\left(x_{i}\right)-y_{i}\right) F\left(\frac{y_{i}-\mu_{i}-g\left(x_{i}\right)}{\sigma_{i}}\right)-\sigma_{i} f\left(\frac{y_{i}-\mu_{i}-g\left(x_{i}\right)}{\sigma_{i}}\right)+y_{i}\right] \\
+ & \alpha_{i}\left[\left(1-F\left(\frac{y_{i}-\mu_{i}-g\left(x_{i}\right)}{\sigma_{i}}\right)\right)\left(y_{i}-\mu_{i}-g\left(x_{i}\right)\right)-\sigma_{i} f\left(\frac{y_{i}-\mu_{i}-g\left(x_{i}\right)}{\sigma_{i}}\right)\right] \\
- & \beta_{i}\left[\left(y_{i}-\mu_{i}-g\left(x_{i}\right)\right) F\left(\frac{y_{i}-\mu_{i}-g\left(x_{i}\right)}{\sigma_{i}}\right)+\sigma_{i} f\left(\frac{y_{i}-\mu_{i}-g\left(x_{i}\right)}{\sigma_{i}}\right)\right]-e_{i} y_{i}-\sum_{j=1}^{k_{i}} c_{i j} x_{i j}-\lambda x_{i}(17) \\
& x_{i j} \leq h_{i j}^{U} w_{i j} \quad(\forall j) \\
& x_{i j} \geq h_{i j}^{L} w_{i j} \quad(\forall j) \\
& \sum_{j=1}^{k_{i}} w_{i j}=1 \\
& x_{i}=\sum_{j=1}^{k_{i}} x_{i j} \\
& x_{i} \geq 0, x_{i j} \geq 0, y_{i} \geq 0, z_{i} \geq 0 \quad(\forall j) \\
& w_{i j} \in\{0,1\} \quad(\forall j)
\end{aligned}
$$

The constraints (20) ensure that for each product $i$, only one of $x_{i j}$ is nonzero. If $w_{i j}=1$, the segment $j$ is applied, then $x_{i}=x_{i j}$. Then, in order to solve $\left(L P_{i}\right)$ effectively, the solution of sub-problems for each segment $\left(L P_{i j}\right)$ is solved firstly. The subproblem for each segment $\left(L P_{i j}\right)$ is formulated by relaxing the constraints $(20)$ and replacing $x_{i}$ with $x_{i j}$. The sub-problem associated with the segment $j$ for product $i$ is as follows.

$$
\begin{aligned}
& \left(L P_{i j}\right) \quad \max L_{i j}=r_{i}\left[\left(\mu_{i}+g\left(x_{i j}\right)-y_{i}\right) F\left(\frac{y_{i}-\mu_{i}-g\left(x_{i j}\right)}{\sigma_{i}}\right)-\sigma_{i} f\left(\frac{y_{i}-\mu_{i}-g\left(x_{i j}\right)}{\sigma_{i}}\right)+y_{i}\right] \\
& +\alpha_{i}\left[\left(1-F\left(\frac{y_{i}-\mu_{i}-g\left(x_{i j}\right)}{\sigma_{i}}\right)\right)\left(y_{i}-\mu_{i}-g\left(x_{i j}\right)\right)-\sigma_{i} f\left(\frac{y_{i}-\mu_{i}-g\left(x_{i j}\right)}{\sigma_{i}}\right)\right] \\
& -\beta_{i}\left[\left(y_{i}-\mu_{i}-g\left(x_{i j}\right)\right) F\left(\frac{y_{i}-\mu_{i}-g\left(x_{i j}\right)}{\sigma_{i}}\right)+\sigma_{i} f\left(\frac{y_{i}-\mu_{i}-g\left(x_{i j}\right)}{\sigma_{i}}\right)-e_{i} y_{i}-c_{i j} x_{i j}-\lambda x_{i j}\right] \\
& \text { s. t. } h_{i j}^{L} \leq x_{i j} \leq h_{i j}^{U}
\end{aligned}
$$

Let $x_{i j}^{+}$be the optimal solution for the sub-problem $\left(L P_{i j}\right)$, then the maximum objective function value of the subproblem $\left(L P_{i}\right)$ is

$$
L_{i}^{*}=\max \left\{L_{i j}\left(x_{i j}^{+}\right), j=1, \ldots, k_{i}\right\}
$$

The maximum value of $\left(L P_{i j}\right)$ for $j=1, \ldots, k_{i}$ is adopted as the solution of $\left(L P_{i}\right)$. The sub-problem $\left(L P_{i j}\right)$ is a classical newsboy model with the lower and upper bounds to the investment amount. To solve the problem, we first ignore the bounds of variable $x_{i j}$. Then the optimal solution $\left(x_{i j}^{*}, y_{i}^{*}\right)$ to the unconstrained problem should satisfy the following equations where $\left(F\left(X_{i j}^{*}\right)=\frac{y_{i}^{*}-\mu_{i}-g\left(x_{i j}^{*}\right)}{\sigma_{i}}\right)$

$$
\left\{\begin{array}{l}
\frac{\partial L_{i j}}{\partial x_{i j}^{*}}=g^{\prime}\left(x_{i j}^{*}\right)\left(r_{i}+\alpha_{i}+\beta_{i}\right) F\left(X_{i j}^{*}\right)-\left(\alpha_{i}+c_{i j}\right)-\lambda=0 \\
\frac{\partial L_{i j}}{\partial y_{i}^{*}}=-\left(r_{i}+\alpha_{i}+\beta_{i}\right) F\left(X_{i j}^{*}\right)+\left(r_{i}+\alpha_{i}-e_{i}\right)=0
\end{array}\right.
$$


We can always obtain the optimal solution $\left(x_{i j}^{*}, y_{i}^{*}\right)$ by (27) and (28) from the following Proposition 1.

Proposition 1 The objective function $L_{i j}$ is concave if and only if $0<m<1$, and $\left(r_{i}+\alpha_{i}+\beta_{i}\right) F\left(X_{i j}\right)>\alpha_{i}$

Proof We define $D$ as a Hessian matrix and $D_{n}$ as a principal minor.

We assume $g\left(x_{i j}\right)=a x_{i j}^{m}$ ( $n$ is a natural number). Then it can say the following:

$$
L_{i j} \text { is concave } \Leftrightarrow(-1)^{m} D_{m}>0
$$

Firstly, we derive $D_{1}$ as follows.

$$
\begin{aligned}
D_{1} & =\frac{\partial^{2} L_{i j}}{\partial x_{i j}^{2}}=a^{2} m(m-1) x_{i j}^{m-2} P F\left(X_{i j}\right)-a^{2} \frac{m x^{2 m-2}\left(x_{i j}\right)}{\sigma_{i}} P f\left(X_{i j}\right)-a^{2} \alpha_{i} m(m-1) x_{i j}^{m-2} \\
& =a^{2}\left(P F\left(X_{i j}\right)-\alpha_{i}\right) m(m-1) x_{i j}^{m-2}-a^{2} \frac{P f\left(X_{i j}\right)}{\sigma_{i}} m x_{i j}^{m-1} \\
& =a^{2} m x_{i j}^{m-2}\left\{\left(P F\left(X_{i j}\right)-\alpha_{i}\right)(m-1)-\frac{P f\left(X_{i j}\right)}{\sigma_{i}} x_{i j}\right\}
\end{aligned}
$$

where, $P=r_{i}+\alpha_{i}+\beta_{i}$.

We assume that $G_{1}\left(x_{i j}\right)=\left(P F\left(X_{i j}\right)-\alpha_{i}\right)(m-1)-\frac{P f\left(X_{i j}\right)}{\sigma_{i}} x_{i j}$. Because $m x_{i j}^{m-2}>0$, we examine the plus or minus sign of $G_{1}$.

$$
\frac{\partial G_{1}\left(x_{i j}\right)}{\partial x_{i j}}=-(m-1) \operatorname{Pf}\left(X_{i j}\right)\left(\frac{a m x_{i j}^{m-1}}{\sigma_{i}}\right)-\frac{X_{i j} P f\left(X_{i j}\right)}{\sigma_{i}} x_{i j}\left(\frac{a m x_{i j}^{m-1}}{\sigma_{i}}\right)-\frac{P f\left(X_{i j}\right)}{\sigma_{i}}<0
$$

$G_{1}(x)$ is a decreasing function. Therefore, if $G_{1}(0)<0$, then $D_{1}<0$ where $G_{1}(0)=(m-1)\left(P F\left(\frac{y-\mu}{\sigma}\right)-\alpha_{i}\right)$. In order to satisfy that $G_{1}<0$, we need to assume that $0<m<1$. This is because that $P F\left(\frac{y-\mu}{\sigma}\right)>\alpha_{i}$.

Next, we derive $D_{2}$ as follows.

$$
\begin{aligned}
D_{2}= & \frac{\partial^{2} L_{i j}}{\partial x_{i j}^{2}} \frac{\partial^{2} L_{i j}}{\partial y_{i}^{2}}-\frac{\partial^{2} L_{i j}}{\partial x_{i j} \partial y_{i}} \frac{\partial^{2} L_{i j}}{\partial y_{i} \partial x_{i j}} \\
= & \frac{a^{2} m(m-1) x_{i j}^{m-2}}{\sigma_{i}} P^{2} F\left(X_{i j}\right) f\left(X_{i j}\right)+\frac{a^{2} m x_{i j}^{m-1}}{\sigma_{i}^{2}} P^{2} f^{2}\left(X_{i j}\right) m x_{i j}^{m-1}+\frac{a^{2} \alpha_{i}}{\sigma_{i}} P f\left(X_{i j}\right) m(m-1) x_{i j}^{m-2} \\
& -a^{2} m^{2} x_{i j}^{2 m-2} P^{2} f^{2}\left(X_{i j}\right) \frac{1}{\sigma_{i}^{2}} \\
= & \frac{a^{2} m(m-1) x_{i j}^{m-2}}{\sigma_{i}} \operatorname{Pf}\left(X_{i j}\right)\left(-P F\left(X_{i j}\right)+\alpha_{i}\right)
\end{aligned}
$$

Because $P F\left(X_{i j}\right)>\alpha_{i}, D_{2}>0$.

Therefore, if $0<m<1$ is satisfied, then the objective function $L_{i j}$ is concave.

The solution of the unconstrained newsboy problem may not satisfy the bounds. If the solution of the unconstrained problem satisfies the bounds, it is optimal for the sub-problem $\left(L P_{i j}\right)$. Otherwise, the solution of the sub-problem $\left(L P_{i j}\right)$ is one of the bounds as proposed in the following Proposition 2.

Proposition 2 Let $x_{i j}^{+}$and $x_{i j}^{*}$ be the optimal solutions of sub-problem $\left(L P_{i j}\right)$ with and without bound constraints (25), respectively. $x_{i j}^{*}$ is evaluated as (27) and (28) if $L_{i j}$ is concave. Then we have:

(i) If the solution $x_{i j}^{*}$ satisfies the bound constraints, i.e., $h_{i j}^{L} \leq x_{i j} \leq h_{i j}^{U}$ then $x_{i j}^{+}=x_{i j}^{*}$.

(ii) If $x_{i j} \geq h_{i j}^{U}$, then $x_{i j}=h_{i j}^{U}$.

(iii)If $x_{i j} \leq h_{i j}^{L}$, then $x_{i j}=h_{i j}^{L}$.

Proof (i) The statement holds straightforwardly.

(ii) Assume that $L_{i j}$ is concave. It follows that the function is monotonic increasing for $x_{i j}<x_{i j}^{*}$. Because $x_{i j}^{*} \geq h_{i j}^{U}$ and $h_{i j}^{U} \geq h_{i j}^{L}$, we have $L_{i j}\left(\right.$ for $\left.x_{i j}=h_{i j}^{U}\right)>L_{i j}\left(\right.$ for $x_{i j}=h_{i j}^{L}$ ). Therefore $x_{i j}^{+}=h_{i j}^{U}$.

(iii) Similar to (ii), the function is monotonic decreasing for $x_{i j}>x_{i j}^{*}$. Because $x_{i j} \leq h_{i j}^{L}$ and $h_{i j}^{U} \geq h_{i j}^{L}$, we have $x_{i j}^{+}=h_{i j}^{L}$.

Proposition 2 provides an algorithm to solve the optimization problem $\left(L P_{i j}\right)$. We can find the optimal solution of $\left(L P_{i}\right)$ by solving all $\left(L P_{i j}\right)$. According to Proposition 2, we design the following Algorithm 1 to solve the sub-problem $\left(L P_{i}\right)$. 
Algorithm 1. Algorithm to solve sub-problems $\left(L P_{i}\right)$

Step 1 Let $j=1$.

Step 2 Use (27) and (28) to evaluate the optimal investment amount $x_{i j}^{*}$ of the unconstrained sub-problem $\left(L P_{i j}\right)$.

Step 3 Check the investment bound constraints: If the solution $x_{i j}^{*}$ is realizable, then $x_{i j}^{+}=x_{i j}^{*}$ and go to Step 5 .

Step 4 If $x_{i j} \geq h_{i j}^{U}$, then $x_{i j}^{+}=h_{i j}^{U}$; otherwise $x_{i j}^{+}=h_{i j}^{L}$. Let $j=j+1$, and go to Step 2 .

Step 5 Compare the objective function values of all solutions and choose the best one as the solution of the problem $\left(L P_{i}\right)$, i.e.,

$$
L_{i}^{*}=\max \left\{L_{i j}, j=1, \ldots, k_{i}\right\}, \text { and } x_{i j}^{*}=\operatorname{argmax}\left\{L_{i j}, j=1, \ldots, k_{i}\right\}
$$

\subsection{Heuristics to construct a feasible solution}

The final solution obtained by Algorithm 1 may not be feasible in most cases violating the total quantity of investment amount. We provide a heuristic to construct a feasible solution to obtain a lower bound from the last Lagrangian dual solutions because the original problem is the maximization problem. On the other hand, some feasible solutions are generated during the solving process. To find a better solution, we present a heuristic to improve the feasible solution. The basic idea is to use the marginal expected net benefit per unit capacity (MENBUC) allocated to each product item (Zhang, 2010). If the total amount of the investment is not reached to the upper limit, we can have more benefit by investing the rest amount to the products having more MENBUC. This is because the solution of $\left(L P_{i}\right)$ can be closer to the optimal solution $x_{i}^{*}$. According to (15), we can obtain the expected benefit for each product $J_{i}$.

$$
\begin{aligned}
J_{i}= & r_{i}\left[\left(\mu_{i}+g\left(x_{i}\right)-y_{i}\right) F\left(X_{i}\right)-\sigma_{i} f\left(X_{i}\right)+y_{i}\right]+\alpha_{i}\left[\left(1-F\left(X_{i}\right)\right)\left(y_{i}-\mu_{i}-g\left(x_{i}\right)\right)-\sigma_{i} f\left(X_{i}\right)\right] \\
- & \beta_{i}\left[\left(y_{i}-\mu_{i}-g\left(x_{i}\right)\right) F\left(X_{i}\right)+\sigma_{i} f\left(X_{i}\right)\right]-e_{i} y_{i}-\sum_{j=1}^{k_{i}} c_{i j} x_{i j} \quad \text { where } X_{i}=\frac{y_{i}-\mu_{i}-g\left(x_{i}\right)}{\sigma_{i}}
\end{aligned}
$$

By differentiating (33) with respect to variable $x_{i}$, we can obtain the MENBUC for each product $i$.

$$
\text { MENBUC }: g^{\prime}\left(x_{i}\right)\left(r_{i}+\alpha_{i}+\beta_{i}\right) F\left(X_{i}\right)-\left(\alpha_{i} g\left(x_{i}\right)+c_{i}\left(x_{i}\right)\right), \quad \forall i
$$

where $c_{i}\left(x_{i}\right)$ is the unit investment cost associated with the investment amount $x_{i}$.

If the total quantity of investment is greater than the upper limit, a feasible solution cannot be obtained. In that case, we choose the product according to the increasing order of MENBUC. In other words, the product with less profitable is chosen until feasible solutions are obtained.

Algorithm 2. Steps for constructing a feasible solution: Starting from the final solution of Lagrangian dual approach, if it is infeasible, we construct a feasible solution to obtain a lower bound as follows:

Step 1 Compute MENBUC for each product $i$.

Step 2 Sort the MENBUCs in an increasing order.

Step 3 Choose the product according to the order, and reduce the investment level as follows:

$x_{i}=\max \left[x_{i}+\left(H-\sum_{i=1}^{n} x_{i}\right), h_{i j}^{L}\right]$

until the upper limit is satisfied. $J\left(x_{i}\right)$ provides the tight lower bound of the original problem.

Step 4 Update the solution.

If the total quantity of investment does not reach to the upper limit, a better solution may be obtained. In that case, we choose the product according to the decreasing order of MENBUC. In other words, the product with more profitable is chosen until solutions satisfy the constraints. Algorithm 3 as follows:

Algorithm 3. Steps for improving solution: Starting from the current feasible solution, if the investment constraint is not tight, we improve the solution as follows:

Step 1 Compute MENBUC for each product $i$.

Step 2 Sort the MENBUCs in a decreasing order.

Step 3 Choose the product according to the order, and increase the investment level as follows:

$x_{i}=\min \left[x_{i}+\left(H-\sum_{i=1}^{n} x_{i}\right), x_{i}^{*}\right]$

until the upper limit of investment is tight. $J\left(x_{i}\right)$ provides the tight lower bound of the original problem.

Step 4 Update the solution.

In Step 4, the updated solution is compared with the current optimal solution of the subproblem. Then, $x_{i}$ is replaced with a better solution of the two solutions. 


\subsection{Solution of Lagrangian dual problem}

The dual problem $(D P)$ of the original problem $(P)$ is as follows.

$$
\begin{aligned}
& (D P) \quad \min \{\max L \mid(2)-(9)\} \\
& \text { s.t. } \quad \lambda \geq 0
\end{aligned}
$$

After the Lagrangian relaxation problem is solved at each iteration, Lagrangian multiplier $\lambda$ is updated in order to find the optimal value of $\lambda$. We update it to solve the Lagrangian dual problem $(D P)$. The subgradient search updates the Lagrangian multiplier by $\lambda^{t+1}=\max \left(\lambda^{t}-s d, 0\right)$ where the subgradient $d$ and step size $s$ are as follows.

$$
\begin{aligned}
& d=H-\sum_{i=1}^{n} x_{i} \\
& s=\frac{\theta(U B-L B)}{d^{2}},
\end{aligned}
$$

where $U B$ and $L B$ are the updated upper and lower bounds at the current iteration, respectively, and $\theta$ is the step-size parameter.

The overall algorithm of the Lagrangian relaxation approach is described in the Algorithm 4.

Algorithm 4. The Lagrangian relaxation algorithm is as follows.

Step 1 Set an initial Lagrangian multiplier $\lambda^{0}$, and the number of iterations $t=0$.

Step 2 Set the Lagrangian relaxation problem.

Step 3 Solve the relaxed sub-problems, for $i=1, \ldots, n$ and obtain the solution $x_{i}^{*}, i=1, \ldots, n$ by Algorithm 1 .

Step 4 Evaluate the value of the upper bound in (16).

Step 5 Generate a feasible solution from the relaxed solution and evaluate the value of the lower bound by Algorithm 2 or Algorithm 3.

Step 6 Update Lagrangian multiplier $\lambda^{t+1}=\max \left(\lambda^{t}-s d, 0\right)$ by using the subgradient method in (37) and (38).

Step 7 Check the condition of convergence: if the condition is satisfied, the algorithm is finished. Otherwise, $t=t+1$ and go to Step 2 .

In the Algorithm 4, the condition of convergence in Step 7 is that the difference of UB and LB is less than 1.0 or the number of iterations reaches to a maximum number of iterations. We use the maximum number of iterations as 1000 in the computational experiments.

\section{Computational experiments}

In this section, computational experiments are conducted in order to evaluate the performance of our Lagrangian relaxation approach. The original problem is coded by the mixed-integer nonlinear programming problem (MINLP). On the other hand, the sub-problem is a nonlinear programming problem (NLP). The optimal solutions of the subproblems can be obtained from the solution of (NLP). Then, the approximate solutions can be obtained from the solutions of the subproblems and heuristics. We assume that $g\left(x_{i}\right)=\sqrt{x_{i}}$ as an example. The experiments are performed by Intel(R) Core(TM) i7-2700 CPU 3.50GHz. The program is coded by the General Algebraic Modeling System (GAMS) Version 23.7. Both problems are solved by a commercial solver with LINDOGLOBAL. In order to compute an integral function, we utilize the error function which describes an integral of the standard normal distribution. The average of the demand $\mu_{i}$ is 15 , the variance $\sigma_{i}^{2}$ is 2 . Table 1 shows the upper limit of investment. Table 2 shows the parameters of 10 types of products.

Table 1 The upper limit of the total amount of investment $H$

\begin{tabular}{c|cccc}
\hline The number of product $i$ & 2 & 5 & 10 & 100 \\
\hline$H$ & 15000 & 25000 & 50000 & 50000 \\
\hline
\end{tabular}

Tables 3-6 show the upper and lower bound of the investment amount of product $i$ on segment $j$. Tables 7 and 8 show the unit investment cost of product $i$ on segment $j$. We assume that the unit investment cost is larger when the amount of investment is larger.

Fig. 3 shows the transitions of the value of the upper bound (UB) and the lower bound (LB) in the case with $n=$ $10, k_{i}=2$. It shows that the upper bound and lower bound values for the proposed method gradually approach each other. 
Table 2 Parameters for 10 types of products

\begin{tabular}{c|cccccccccc}
\hline Product $i$ & 1 & 2 & 3 & 4 & 5 & 6 & 7 & 8 & 9 & 10 \\
\hline The unit sales revenue of product $i: r_{i}$ & 715 & 702 & 710 & 718 & 709 & 750 & 790 & 760 & 770 & 680 \\
The unit shortage penalty of product $i: \alpha_{i}$ & 50 & 60 & 55 & 58 & 40 & 55 & 65 & 40 & 80 & 50 \\
The unit overstocking cost of product $i: \beta_{i}$ & 40 & 25 & 30 & 40 & 45 & 30 & 40 & 36 & 50 & 40 \\
The unit production cost of product $i: e_{i}$ & 128 & 125 & 132 & 135 & 120 & 140 & 115 & 150 & 140 & 110 \\
\hline
\end{tabular}

Table 9 shows the results of the investment amount, the production quantity, the sales revenue, the overstocking cost, the shortage penalty, the production cost, and the investment cost.

Table 10 shows that comparison of UB, LB, computational time, and the duality gap for the proposed method and the MINLP (LINDOGLOBAL) when the number of products and investment segments are changed. Here, MINLP represents the case in which the original problem is solved directly by a general-purpose solver LINDOGLOBAL. In Table 10, the value in ( ) shows (the number of products, the number of investment segments). Also, if the computational time is reached 3600 seconds, the computation is finished. (3600) in time means that the computation time is reached in 3600 seconds and the tentative solution is obtained. The number in the left-hand side of (3600) is the computational time when the maximum lower bound is obtained. From the results, the computation time for MINLP increases and the accurate lower bound cannot be obtained when the number of products increased. On the other hand, the computation time for the proposed method is not much increased and the lower bound is significantly better than that of MINLP when the number of products increased. Furthermore, in the proposed method, the computation time is not increased and the lower bound is better even when the number of investment segments is increased. The value of the upper bound cannot be obtained by MINLP due to the shortage of computation time of 3600 seconds. Therefore, we can confirm that the proposed method is more effective than the MINLP when the problem scale is large.

Table 11 shows the computational experiments for different number of segments. From the results, when the number of investment segments is large, the duality gap of LB and UB is 0 but the LB becomes lower. This is because the investment cost is larger when the number of invest segments is increased.

\subsection{Sensitivity analysis}

In this section, computational experiments are conducted to illustrate the characteristics of the proposed model. We focus on the decisions of the manufacturer to observe how the decisions influence manufacturing planning in the model. In order to analyze the impact of parameters, we report the experiments to illustrate how each cost influences investment, production and profits in the model.

Six tests in the case with $n=2, k_{i}=5$ are used to analyze the impact of unit revenue $r_{i}$, shortage penalty $\alpha_{i}$, overstocking cost $\beta_{i}$, mean of demand $\mu_{i}$, deviation of demand $\sigma_{i}$, respectively. For each test, only one parameter is changed while other parameters are fixed. There are four cases where we adjust one parameter four times in one test. We consider two types of finished products for the experiments. However, we only change one parameter once for one type of products for each case. For example, in Test 1, we change the unit revenue $r_{i}$, once for each case. The results of the sensitivity analysis are presented in Table 12. From the results of Table 12, we can observe that the profit increases once unit one type of sales revenue is increased. In Cases 3, 4 of Test 1, the production quantity of product 2 increases. The total profit is increased with the increase of sales revenue. Test 2 and Test 3 are conducted to illustrate the impact of uncertain demand on planning decisions, while the manufacturer may encounter shortage or overstocking.

From Test 2, it implies that the production quantity is increased if the manufacturer increases the shortage penalties of one type of products. The increase of overstocking costs ensures that the production quantity always decreases in Test 3. From Test 2 and Test 3, with the increase of the shortage penalties and overstocking costs, the total profit is decreased. We also analyze the influences of uncertainty in Test 4 and Test 5 . We can notice that the production quantity is increased and the total profit is increased if the mean value of demand is increased in Test 4 . However, Test 5 shows that with the increase of deviation of demand, the overstocking costs and the shortage penalties are increased and the revenue is decreased. Therefore, the total profit decreases with the increase of deviation of demand. In Test 6, Cases 1-3 show that if the upper limit of the total quantity of investment is decreased, the investment amount is decreased. However, Cases 1,4 show that the amount of investment is not always increased if the upper limit of the total quantity of investment is increased. This is because if the amount of investment is increased, the more investment cost is required. Therefore, the total profit is decreased when the upper limit of the total amount of investment. From the above results, we can conclude that the manufacturer should design the production planning in order to increase profits based on the result of computational experiments according to different strategies of decisions. 
Aoyama, Nishi and Zhang, Journal of Advanced Mechanical Design, Systems, and Manufacturing, Vol.11, No.2 (2017)

Table $3 h_{i j}^{U}$ : The upper bound of the investment amount for 2 segments

\begin{tabular}{c|cc}
\hline & segment 1 & segment 2 \\
\hline product 1 & 2500 & 9000 \\
product 2 & 1400 & 9000 \\
product 3 & 3550 & 9000 \\
product 4 & 2410 & 9000 \\
product 5 & 2360 & 9000 \\
product 6 & 2500 & 9000 \\
product 7 & 1900 & 9000 \\
product 8 & 3000 & 9000 \\
product 9 & 2710 & 9000 \\
product 10 & 2000 & 9000 \\
\hline
\end{tabular}

Table $4 h_{i j}^{L}$ : The lower bound of the investment amount for 2 segments

\begin{tabular}{c|cc}
\hline & segment 1 & segment 2 \\
\hline product 1 & 0.0 & 2500 \\
product 2 & 0.0 & 1400 \\
product 3 & 0.0 & 3550 \\
product 4 & 0.0 & 2410 \\
product 5 & 0.0 & 2360 \\
product 6 & 0.0 & 2500 \\
product 7 & 0.0 & 1900 \\
product 8 & 0.0 & 3000 \\
product 9 & 0.0 & 2710 \\
product 10 & 0.0 & 2000 \\
\hline
\end{tabular}

Table $5 h_{i j}^{U}$ : The upper bound of the investment amount for 5 segments

\begin{tabular}{l|ccccc}
\hline & segment 1 & segment 2 & segment 3 & segment 4 & segment 5 \\
\hline product 1 & 500 & 2000 & 5000 & 7500 & 9000 \\
product 2 & 400 & 3000 & 5100 & 7700 & 9000 \\
product 4 & 500 & 2200 & 5500 & 7200 & 9000 \\
product 5 & 300 & 3000 & 4100 & 7000 & 9000 \\
product 5 & 500 & 3500 & 5700 & 7900 & 9000 \\
\hline
\end{tabular}

Table $6 h_{i j}^{L}$ : The lower bound of the investment amount for 5 segments

\begin{tabular}{l|ccccc}
\hline & segment 1 & segment 2 & segment 3 & segment 4 & segment 5 \\
\hline product 1 & 0.0 & 500 & 2000 & 5000 & 7500 \\
product 2 & 0.0 & 400 & 3000 & 5100 & 7700 \\
product 3 & 0.0 & 500 & 2200 & 5500 & 7200 \\
product 4 & 0.0 & 300 & 3000 & 4100 & 7000 \\
product 5 & 0.0 & 500 & 3500 & 5700 & 7900 \\
\hline
\end{tabular}

Table $7 c_{i j}$ : The unit investment cost for 2 segments

\begin{tabular}{c|cc}
\hline & segment 1 & segment 2 \\
\hline product 1 & 1.2 & 1.5 \\
product 2 & 1.1 & 1.5 \\
product 3 & 1.15 & 1.45 \\
product 4 & 1.1 & 1.47 \\
product 5 & 1.05 & 1.5 \\
product 6 & 1.25 & 1.35 \\
product 7 & 1.13 & 1.75 \\
product 8 & 1.11 & 1.45 \\
product 9 & 1.01 & 1.47 \\
product 10 & 1.06 & 1.55 \\
\hline
\end{tabular}

Table $8 \quad c_{i j}$ : The unit investment cost for 5 segments

\begin{tabular}{l|ccccc}
\hline & segment 1 & segment 2 & segment 3 & segment 4 & segment 5 \\
\hline product 1 & 1 & 1.5 & 3 & 3.5 & 4.0 \\
product 2 & 1 & 1.5 & 3 & 3.6 & 4.0 \\
product 3 & 1 & 1.5 & 3 & 3.5 & 3.6 \\
product 4 & 1 & 1.2 & 2.5 & 3.6 & 4.1 \\
product 5 & 1 & 1.4 & 3.1 & 3.5 & 3.7 \\
\hline
\end{tabular}


Aoyama, Nishi and Zhang, Journal of Advanced Mechanical Design, Systems, and Manufacturing, Vol.11, No.2 (2017)

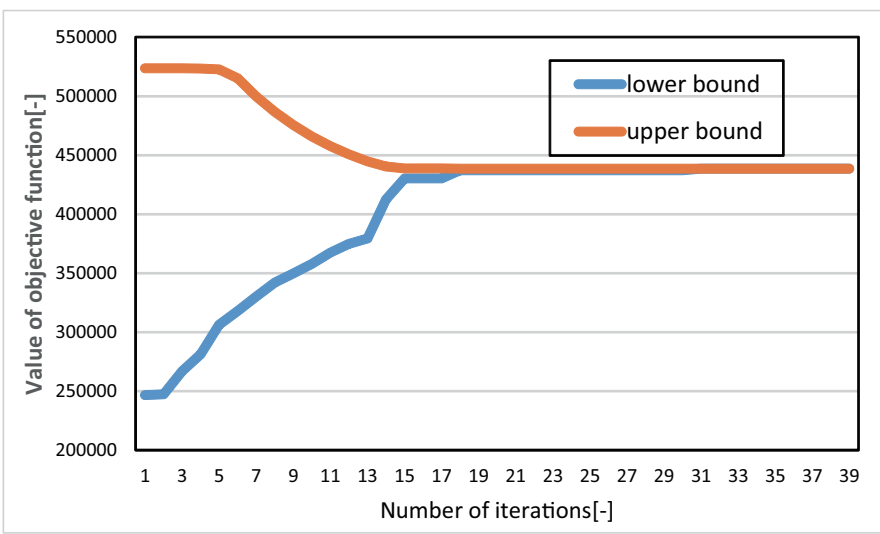

Fig. 3 Transitions of the value of UB and LB

Table 9 Results of decision variables in the case with $n=10, k_{i}=2$

\begin{tabular}{c|cccccccccc}
\hline Product $i$ & 1 & 2 & 3 & 4 & 5 & 6 & 7 & 8 & 9 & 10 \\
\hline The investment amount for producti: $x_{i}$ & 4865.63 & 4701.26 & 3550.00 & 4818.75 & 5083.53 & 5650.05 & 5732.41 & 5381.53 & 5685.37 & 4480.76 \\
The production quantity for product $i: y_{i}$ & 86.38 & 85.32 & 76.26 & 85.89 & 87.95 & 91.82 & 92.60 & 89.89 & 92.01 & 83.66 \\
The sales revenue of product $i$ & 60430.55 & 58515.76 & 54280.48 & 61007.73 & 61969.29 & 67453.81 & 71516.11 & 66958.12 & 69424.81 & 55571.37 \\
The overstocking cost of product $i$ & 74.31 & 49.03 & 56.98 & 87.06 & 84.53 & 56.58 & 82.77 & 64.22 & 92.22 & 77.46 \\
The shortage penalty of product $i$ & 11.79 & 12.60 & 10.13 & 18.80 & 9.22 & 12.56 & 12.09 & 10.25 & 19.15 & 10.79 \\
The production cost of product $i$ & 11056.12 & 10664.64 & 10065.83 & 12454.02 & 10553.63 & 12855.44 & 10648.54 & 13482.98 & 12880.92 & 9202.51 \\
The investment cost for product $i$ & 7298.44 & 7051.89 & 4082.50 & 7083.56 & 7625.29 & 7627.57 & 10031.72 & 7803.22 & 8357.50 & 6945.18 \\
\hline
\end{tabular}

Table 10 Computational results of the proposed method and MINLP solver (LINDOGLOBAL)

\begin{tabular}{ccccc}
\hline Case $\left(n, k_{i}\right)$ & LB[-] & UB[-] & time[s] & duality gap[\%] \\
\hline Proposed method $(2,2)$ & 91876.95 & 95053.54 & 12.748 & 3.45 \\
MINLP $(2,2)$ & 93315.94 & - & 0.326 & - \\
Proposed method (2, 5) & 70180.50 & 70180.50 & 10.749 & 0 \\
MINLP $(2,5)$ & $(70180.50)$ & - & $0.5(3600)$ & - \\
Proposed method (5, 2) & 210768.36 & 210849.11 & 12.044 & 0.038 \\
MINLP $(5,2)$ & 201745.75 & - & 3.89 & - \\
Proposed method (10, 2) & 438503.98 & 438641.25 & 12.539 & 0.031 \\
MINLP (10, 2) & $(430112.70)$ & - & $9.0(3600)$ & - \\
Proposed method (10, 5) & 373649.56 & 373649.56 & 16.502 & 0 \\
MINLP $(10,5)$ & $(371419.26)$ & - & $4.5(3600)$ & - \\
Proposed method (100, 2) & 4132747.23 & 4133356.29 & 500.696 & 0.014 \\
MINLP $(100,2)$ & $(2450327.09)$ & - & $575(3600)$ & - \\
Proposed method (100, 5) & 3476997.12 & 3476997.12 & 67.529 & 0 \\
MINLP $(100,5)$ & - & - & - & - \\
\hline
\end{tabular}


Aoyama, Nishi and Zhang, Journal of Advanced Mechanical Design, Systems, and Manufacturing, Vol.11, No.2 (2017)

Table 11 Computational results for different number of investment segments

\begin{tabular}{ccccc}
\hline Case $\left(n, k_{i}\right)$ & LB[-] & UB[-] & time[s] & duality gap[\%] \\
\hline Proposed method $(2,2)$ & 91876.95 & 95053.54 & 12.748 & 3.45 \\
Proposed method $(2,5)$ & 70180.50 & 70180.50 & 10.749 & 0 \\
Proposed method $(2,7)$ & 70862.92 & 70862.92 & 12.094 & 0 \\
Proposed method $(2,10)$ & 65494.67 & 65494.67 & 12.298 & 0 \\
\hline
\end{tabular}

Table 12 Computational results of the sensitivity analysis

\begin{tabular}{|c|c|c|c|c|c|c|c|c|}
\hline Test 1 & \multicolumn{2}{|c|}{$\begin{array}{c}\text { Effects of unit revenue } \\
\text { Case } 1\end{array}$} & \multicolumn{2}{|c|}{ Case 2} & \multicolumn{2}{|c|}{ Case 3} & \multicolumn{2}{|c|}{ Case 4} \\
\hline Unit revenue & Product 1 & Product 2 & Product 1 & Product 2 & Product 1 & Product 2 & Product 1 & Product 2 \\
\hline$r_{i}$ & 715 & 702 & 715 & 740 & 715 & 800 & 830 & 830 \\
\hline Revenue & 61114.53 & 48832.73 & 61114.53 & 51485.12 & 61114.53 & 68986.62 & 70974.81 & 71579.77 \\
\hline Overstocking cost & 74.31 & 49.03 & 74.31 & 50.37 & 74.31 & 52.33 & 80.39 & 53.26 \\
\hline Shortage penalty & 11.79 & 12.60 & 11.79 & 11.87 & 11.79 & 10.86 & 9.94 & 10.42 \\
\hline Investment cost & 15000 & 4500 & 15000 & 4500 & 15000 & 15300 & 15000 & 15300 \\
\hline Production cost & 11178.57 & 8940.46 & 11178.57 & 8948.65 & 11178.57 & 11040.83 & 11202.77 & 11046.39 \\
\hline Total profit & \multicolumn{2}{|c|}{70180.50} & \multicolumn{2}{|c|}{72824.10} & \multicolumn{2}{|c|}{77432.46} & \multicolumn{2}{|c|}{89851.42} \\
\hline Test 2 & \multicolumn{6}{|c|}{ Effects of shortage penalty } & \multicolumn{2}{|c|}{ Case 4} \\
\hline $\begin{array}{l}\text { Unit shortage penalty } \\
\qquad \alpha_{i}\end{array}$ & $\begin{array}{l}\text { Product } 1 \\
50\end{array}$ & $\begin{array}{l}\text { Product } 2 \\
60\end{array}$ & $\begin{array}{l}\text { Product } 1 \\
50\end{array}$ & $\begin{array}{l}\text { Product } 2 \\
90\end{array}$ & $\begin{array}{c}\text { Product } 1 \\
50\end{array}$ & $\begin{array}{c}\text { Product } 2 \\
130\end{array}$ & $\begin{array}{l}\text { Product } 1 \\
100\end{array}$ & $\begin{array}{c}\text { Product } 2 \\
100\end{array}$ \\
\hline Revenue & 61114.53 & 48832.73 & 61114.53 & 48839.57 & 61114.53 & 48845.83 & 61127.06 & 48841.72 \\
\hline Overstocking cost & 74.31 & 49.03 & 74.31 & 50.09 & 74.31 & 51.11 & 77.07 & 50.44 \\
\hline Shortage penalty & 11.79 & 12.60 & 11.79 & 18.027 & 11.79 & 22.96 & 21.83 & 19.72 \\
\hline Investment cost & 15000 & 4500 & 15000 & 4500 & 15000 & 4500 & 15000 & 4500 \\
\hline Production cost & 11178.57 & 8940.46 & 11178.57 & 8946.97 & 11178.57 & 8953.15 & 11189.65 & 8949.06 \\
\hline Total profit & \multicolumn{2}{|c|}{70180.50} & \multicolumn{2}{|c|}{70174.35} & \multicolumn{2}{|c|}{70168.48} & \multicolumn{2}{|c|}{70161.02} \\
\hline Test 3 & \multicolumn{4}{|c|}{$\begin{array}{l}\text { Effects of overstocking cost } \\
\text { Case } 1 \quad \text { Case } 2\end{array}$} & \multicolumn{2}{|c|}{ Case 3} & \multicolumn{2}{|c|}{ Case 4} \\
\hline $\begin{array}{c}\text { Unit overstocking cost } \\
\beta_{i}\end{array}$ & $\begin{array}{l}\text { Product } 1 \\
\quad 40\end{array}$ & $\begin{array}{l}\text { Product } 2 \\
25\end{array}$ & $\begin{array}{l}\text { Product } 1 \\
40\end{array}$ & $\begin{array}{l}\text { Product } 2 \\
45\end{array}$ & $\begin{array}{l}\text { Product } 1 \\
40\end{array}$ & $\begin{array}{l}\text { Product } 2 \\
55\end{array}$ & $\begin{array}{l}\text { Product } 1 \\
45\end{array}$ & $\begin{array}{l}\text { Product } 2 \\
45\end{array}$ \\
\hline $\begin{array}{c}\rho_{i} \\
\text { Revenue }\end{array}$ & 61114.53 & 48832.73 & 61114.53 & 48812.58 & 61114.53 & 48802.59 & 61109.43 & 48812.58 \\
\hline Overstocking cost & 74.31 & 49.03 & 74.31 & 83.11 & 74.31 & 98.73 & 82.40 & 83.11 \\
\hline Shortage penalty & 11.79 & 12.60 & 11.79 & 14 & & & 12.15 & 14.32 \\
\hline Investment cost & 15000 & 4500 & 15000 & 4500 & 15000 & 4500 & 15000 & 4500 \\
\hline Production cost & 11178.57 & 8940.46 & 11178.57 & 8922.57 & 11178.57 & 8914.31 & 11174.25 & 8922.57 \\
\hline Total profit & 7018 & 0.50 & 701 & 2.44 & 701 & 4.24 & 7013 & 3.22 \\
\hline Test 4 & $\begin{array}{r}\text { Effects of } n \\
\text { Cas }\end{array}$ & 1 & & & & e 3 & & \\
\hline Mean of demand & Product 1 & $\begin{array}{l}\text { Product } 2 \\
15\end{array}$ & Product 1 & $\begin{array}{l}\text { Product } 2 \\
12\end{array}$ & $\begin{array}{l}\text { Product } 1 \\
15\end{array}$ & $\begin{array}{l}\text { Product } 2 \\
10\end{array}$ & $\begin{array}{l}\text { Product } 1 \\
50\end{array}$ & $\begin{array}{c}\text { Product } 2 \\
50\end{array}$ \\
\hline $\begin{array}{c}\mu_{i} \\
\text { Revenue }\end{array}$ & 61114.53 & 48832.73 & 58969.53 & 46726.73 & 61114.53 & 45322.73 & 86139.53 & 73402.73 \\
\hline Overstocking cost & 74.31 & 49.03 & 74.31 & 49.03 & 74.31 & 49.03 & 74.31 & 49.03 \\
\hline Shortage penalty & 11.79 & 12.60 & 11.79 & 12.60 & 11.79 & 12.60 & 11.79 & 12.60 \\
\hline Investment cost & 15000 & 4500 & 15000 & 4500 & 15000 & 4500 & 15000 & 4500 \\
\hline Production cost & 11178.57 & 8940.46 & 10794.57 & 8565.46 & 11178.57 & 8315.46 & 15658.57 & 13315.46 \\
\hline Total profit & 7018 & 0.50 & 666 & 8.50 & 672 & 5.50 & 1109 & 0.50 \\
\hline Test 5 & $\begin{array}{r}\text { Effects of d } \\
\text { Cas }\end{array}$ & eviation of d & emand $\mathrm{Ca}$ & & & e 3 & & 4 \\
\hline $\begin{array}{l}\text { Deviation of demand } \\
\qquad \sigma_{i}\end{array}$ & $\begin{array}{l}\text { Product } 1 \\
2\end{array}$ & $\begin{array}{l}\text { Product } 2 \\
2\end{array}$ & $\begin{array}{c}\text { Product } 1 \\
10\end{array}$ & $\begin{array}{c}\text { Product } 2 \\
10\end{array}$ & $\begin{array}{l}\text { Product } 1 \\
5\end{array}$ & $\begin{array}{c}\text { Product } 2 \\
2\end{array}$ & $\begin{array}{l}\text { Product } 1 \\
0.5\end{array}$ & $\begin{array}{c}\text { Product } 2 \\
0.5\end{array}$ \\
\hline Revenue & 61114.53 & 48832.73 & 60440.12 & 48243.14 & 60861.63 & 48832.73 & 61240.98 & 48943.27 \\
\hline Overstocking cost & 74.31 & 49.03 & 371.54 & 245.17 & 185.77 & 49.03 & 18.58 & 12.26 \\
\hline Shortage penalty & 11.79 & 12.60 & 58.95 & 62.99 & 29.48 & 12.60 & 2.95 & 3.15 \\
\hline Investment cost & 15000 & 4500 & 15000 & 4500 & 15000 & 4500 & 15000 & 4500 \\
\hline Production cost & 11178.57 & 8940.46 & 12008.99 & 9816.15 & 11489.98 & 8940.46 & 11022.87 & 8776.26 \\
\hline Total profit & 7018 & 0.50 & 666 & 9.46 & 694 & 7.04 & 708 & 8.19 \\
\hline Test 6 & Effects of $u$ & pper limit of & the total qu & intity of in & ment & & & \\
\hline $\begin{array}{l}\text { Upper limit of the total } \\
\text { quantity of investment } H\end{array}$ & $\begin{array}{l}\mathrm{Ca} \\
150\end{array}$ & & & e 2 & & e 3 & & \\
\hline Revenue & 61114.53 & 48832.73 & 42532.17 & 48832.73 & 38480.26 & 37331.37 & 61114.53 & 48832.73 \\
\hline Overstocking cost & 74.31 & 49.03 & 74.31 & 49.03 & 74.31 & 49.03 & 74.31 & 49.03 \\
\hline Shortage penalty & 11.79 & 12.60 & 11.79 & 12.60 & 11.79 & 12.60 & 11.79 & 12.60 \\
\hline Investment cost & 15000 & 4500 & 3000 & 4500 & 2289.48 & 2212.14 & 15000 & 4500 \\
\hline Production cost & 11178.57 & 8940.46 & 7851.94 & 8940.46 & 7126.56 & 6892.49 & 11178.57 & 8940.46 \\
\hline Total profit & 7018 & 0.50 & 669 & 4.77 & 655 & 9.38 & 7018 & 0.50 \\
\hline
\end{tabular}




\section{Conclusion}

In this paper, we have developed a production planning model for a single manufacturer with market impact under uncertain demand. The problem is formulated as a mixed nonlinear integer programming model. A solution procedure based on Lagrangian relaxation has been proposed. In the proposed approach, near-optimal solutions are obtained efficiently by utilizing the analytical solution of the newsboy problem. From computational experiments, it has been shown that the proposed approach can derive a near-optimal solution for large scale problems with 100 products with small duality gap with less computational effort than the general-purpose solver. The effectiveness of the proposed method is confirmed. In the future work, we will develop the algorithm to apply the more practical model such as multi-period planning model in order to obtain a more precise value of the lower bound reducing the computational efforts. Furthermore, we need to analyze many types of cases which market impact is considered as an investment.

\section{AppendixA. Stochastic formulations}

The stochastic model assumes that the demand fluctuate. Then, the production quantity $y_{i}$ is the minimum between $z_{i}$ and $y_{i}$ :

$$
\min \left(z_{i}, y_{i}\right)
$$

The sales revenue is $R E_{i}=r_{i} \min \left(z_{i}, y_{i}\right)\left\{\begin{array}{ll}r_{i} z_{i} & \text { if } z_{i} \leq y_{i} \\ r_{i} y_{i} & \text { if } z_{i} \geq y_{i}\end{array}\right.$. The standardized normal variables are defined as $X_{i}=$ $\frac{z_{i}-\mu_{i}}{\sigma_{i}}$ where $\mu_{i}$ denotes the mean of $z_{i}$ and $\sigma_{i}$ denotes the square root of its variance. In the same way, the standardized normal variables are defined as $Y_{i}=\frac{y_{i}-\mu_{i}}{\sigma_{i}}$. The expectation of the sales revenue $E\left[R E_{i}\right]$ is obtained by

$$
E\left[R E_{i}\right]=F\left(Y_{i}\right) E\left[r_{i} z_{i} \mid z_{i} \leq y_{i}\right]+\left(1-F\left(Y_{i}\right)\right) E\left[r_{i} y_{i} \mid z_{i} \geq y_{i}\right]
$$

Therefore,

$$
E\left[R E_{i}\right]=F\left(Y_{i}\right) E\left[r_{i} z_{i} \mid \frac{z_{i}-\mu_{i}}{\sigma_{i}} \leq \frac{y_{i}-\mu_{i}}{\sigma_{i}}\right]+\left(1-F\left(Y_{i}\right)\right) E\left[r_{i} y_{i} \mid \frac{z_{i}-\mu_{i}}{\sigma_{i}} \geq \frac{y_{i}-\mu_{i}}{\sigma_{i}}\right]
$$

$X_{i}=\frac{z_{i}-\mu_{i}}{\sigma_{i}}$ and $Y_{i}=\frac{y_{i}-\mu_{i}}{\sigma_{i}}$ are substituted into (A.3).

$$
E\left[R E_{i}\right]=r_{i} \mu_{i}+r_{i} \sigma_{i} F\left(Y_{i}\right) E\left[X_{i} \mid X_{i} \leq Y_{i}\right]+\left(1-F\left(Y_{i}\right)\right) E\left[Y_{i} \mid X_{i} \geq Y_{i}\right]
$$

In (A.4), $E\left[X_{i} \mid X_{i} \leq Y_{i}\right], E\left[Y_{i} \mid X_{i} \geq Y_{i}\right]$ are as follows:

$$
\begin{aligned}
& E\left[X_{i} \mid X_{i} \leq Y_{i}\right]=\frac{\frac{1}{\sqrt{2 \pi}} \int_{-\infty}^{Y_{i}} X_{i} \exp \left(-\frac{1}{2} X_{i}^{2}\right) d X_{i}}{\frac{1}{\sqrt{2 \pi}} \int_{-\infty}^{Y_{i}} \exp \left(-\frac{1}{2} X_{i}^{2}\right) d X_{i}}=\frac{-1}{F\left(Y_{i}\right)} \frac{\exp \left(-\frac{1}{2} X_{i}^{2}\right)}{\sqrt{2 \pi}}=\frac{-f\left(Y_{i}\right)}{F\left(Y_{i}\right)} \\
& E\left[Y_{i} \mid X_{i} \geq Y_{i}\right]=Y_{i}
\end{aligned}
$$

where $f\left(z_{i}\right)$ is the probability density function followed by the demand $z_{i}$. From (A.5) and (A.6), we can reformulate the expected revenue $E\left[R E_{i}\right]$ :

$$
E\left[R E_{i}\right]=r_{i} \mu_{i}+r_{i} \sigma_{i}\left[-f\left(Y_{i}\right)+\left(1-F\left(Y_{i}\right)\right) Y_{i}\right]
$$

The expectation of shortage penalty:

$$
E\left[S H_{i}\right]=-\alpha_{i}\left\{\mu_{i}+\sigma_{i}\left[-f\left(Y_{i}\right)+\left(1-F\left(Y_{i}\right)\right) Y_{i}\right]-\mu_{i}=-\alpha_{i} \sigma_{i}\left[-f\left(Y_{i}\right)+\left(1-F\left(Y_{i}\right)\right) Y_{i}\right]\right\}
$$

The expectation of overstocking cost:

$$
\begin{aligned}
& E\left[O R_{i}\right]=\beta_{i}\left[y_{i}-\mu_{i}-\sigma_{i}\left[-f\left(Y_{i}\right)+\left(1-F\left(Y_{i}\right)\right) Y_{i}\right]\right]=\beta_{i}\left[Y_{i} \sigma_{i}-\sigma_{i}\left[-f\left(Y_{i}\right)+\left(1-F\left(Y_{i}\right)\right) Y_{i}\right]\right] \\
& \quad=\beta_{i} \sigma_{i}\left[f\left(Y_{i}\right)+F\left(Y_{i}\right) Y_{i}\right]
\end{aligned}
$$

\section{Acknowledgment}

The authors would like to thank the anonymous reviewers for their comments to improve the paper. This research is supported by JSPS KAKENHI (B) 15H02971. 


\section{References}

Aoyama, T. and Nishi, T., A solution procedure based on Lagrangian relaxation for supply chain planning problem with CSR investment, Proceedings of the 2015 Industrial Engineering and Engineering Management, (2015), pp. 16031607.

Cruz, J. M., Dynamics of supply chain networks with corporate social responsibility through integrated environmental decision-making, European Journal of Operational Research, Vol. 184, (2008), pp. 1005-1031.

Cruz, J. M., The impact of corporate social responsibility in supply chain management: Multicriteria decision-making approach, Decision Support Systems, Vol. 48, (2009), pp. 224-236.

Cruz, J. M., Modeling the relationship of globalized supply chains and corporate social responsibility, Journal of Cleaner Production, Vol. 56, (2013), pp. 73-85.

Franz, W., Gustav, F. and Peter M. K., Individual firm and market dynamics of CSR activities, Journal of Economic Behavior $\mathcal{F}$ Organization, Vol. 86, (2013), pp. 169-182.

Giri, B. C. and Sharma, S., Manufacturer's pricing strategy in a two-level supply chain with competing retailers and advertising cost dependent demand, Economic Modelling, Vol. 38, (2014), pp. 102-111.

Hsueh, C., Improving corporate social responsibility in a supply chain through a new revenue sharing contract, International Journal of Production Economics, Vol. 151, (2014), pp. 214-222.

Hsueh, C. and Chang, M.S., Equilibrium analysis and corporate social responsibility for supply chain integration, European Journal of Operational Research, Vol. 190, (2008), pp. 116-129.

Li, S.X., Huang, Z, Zhu, J. and Chau, P.Y.K., Cooperative advertising, game theory and manufacturer-retailer supply chains, Omega, Vol. 30, (2002), pp. 347-357.

Ni, D. and Li, K.W., A game-theoretic analysis of social responsibility conduct in two-echelon supply chains, International Journal of Production Economics, Vol. 138, (2012), pp. 303-313.

Ni, D., Li, K.W. and Tang, X., Social responsibility allocation in two-echelon supply chains: Insights from wholesale price contracts, European Journal of Operational Research, Vol. 207, (2010), pp. 1269-1279.

Nishi, T., Shinozaki, R. and Konishi, M., An augmented Lagrangian approach for distributed supply chain planning for multiple companies, IEEE Transactions on Automation Science and Engineering, Vol. 5, (2008), pp. $259-274$.

Petkov, S.B. and Maranas, C.D., Multiperiod planning and scheduling of multiproduct batch plants under demand uncertainty, Industrial Engineering and Chemistry Research, Vol. 30, (1997), pp. 4864-4881.

SeyedEsfahani, M. M., Biazaran, M. and Ggarakhani. M., A game theoretic approach to coordinate pricing and vertical coop advertising in manufacturer-retailer supply chains, European Journal of Operational Research, Vol. 211, (2011), pp. 263-273.

Shi, J., Zhang, G. and Sha, J., Optimal production planning for a multi-product closed loop system with uncertain demand and return, Computers and Operations Research, Vol. 38, (2011), pp. 641-650.

Yin, S., Nishi, T. and Grossmann, I.E., Optimal quantity discount coordination for supply chain optimization with one manufacturer and multiple suppliers under demand uncertainty, International Journal of Advanced Manufacturing Technology, Vol. 76, (2014), pp. 1173-1184.

Yin, S. and Nishi, T., A solution procedure for mixed-integer nonlinear programming formulation of supply chain planning with quantity discounts under demand uncertainty, International Journal of Systems Science, Vol. 45, (2014), pp. 2354-2365.

Yue, J., Austin, J., Wang, M. C. and Huang, Z., Coordination of cooperative advertising in a two-level supply chain when manufacturer offers discount, European Journal of Operational Research, Vol. 168, (2006), pp. 65-85.

Zhang, G. and Ma, L., Optimal acquisition policy with quantity discounts and uncertain demands, International Journal of Production Research, Vol. 47, (2009), pp. 2409-2425.

Zhang, G., The multi-product newsboy problem with supplier quantity discounts and a budget constraint, European Journal of Operational Research, Vol. 206, (2010), pp. 350-360.

Zhang, J., Gou, Q., Liang, L. and Huang, Z., Supply chain coordination through cooperative advertising with reference price effect, Omega, Vol. 41, (2013), pp. 345-353.

Zhang, W., Li, S., Zhang, D. and Hou, W. On the impact of advertising initiatives in supply chains, European Journal of Operational Research, Vol. 234, (2014), pp. 99-107. 